\title{
Variation of sperm allocation with male size and recovery rate of sperm numbers in spiny king crab Paralithodes brevipes
}

\author{
Taku Sato ${ }^{1, *}$, Masakazu Ashidate ${ }^{2}$, Tadao Jinbo ${ }^{2}$, Seiji Goshima ${ }^{1}$ \\ ${ }^{1}$ Laboratory of Marine Biodiversity, Graduate School of Fisheries Sciences, Hokkaido University, Hakodate, \\ Hokkaido 041-8611, Japan \\ ${ }^{2}$ IAA, FRA, National Center for Stock Enhancement, Akkeshi Station, 2-1 Tsukushikoi, Akkeshi, Hokkaido 088-1160, Japan
}

\begin{abstract}
This study examined whether sperm allocation by males can limit sperm passed to females in fished spiny king crab populations in which large males are selectively fished. We investigated the recovery rate of sperm in vasa deferentia of males of different body sizes, sperm allocation passed to females of different body sizes by males of different body sizes, and sperm allocation in different male:female sex ratios (1:1 or 1:6) by males of different body sizes by laboratory experiments. The recovery rates of sperm were very slow regardless of male size, suggesting that a sperm allocation strategy is important to increase male reproductive success in this species. In large males, the ejaculate size increased significantly with increasing female size, but the ejaculate size of small males did not vary with female size, indicating that small males cannot increase ejaculate size by more than a certain number. Females mated with small males showed significantly lower fertilization rates than females mated with large males. Males showed no difference in pattern of sperm allocation between the different sex ratios in both male size classes. These results suggest that a decrease in mean male size due to male-only fishing would increase the number of females mated with small males without an ability to increase ejaculate size with increasing female size, so that females mating with small males would receive an insufficient sperm supply and have a low fertilization rate due to sperm limitation.
\end{abstract}

KEY WORDS: Sperm limitation $\cdot$ Sperm allocation $\cdot$ Sperm-to-egg ratio $\cdot$ Recovery rate $\cdot$ Male-only fishing $\cdot$ Paralithodes brevipes

\section{INTRODUCTION}

Sperm production is costly and slow in many organisms (e.g. Dewsbury 1982, Pitnick \& Markow 1994). Therefore, males should economize on their sperm by efficiently partitioning it among successive matings depending on the expected reproductive return and future mating opportunities (Dewsbury 1982, Pitnick \& Markow 1994, Warner et al. 1995, Parker et al. 1997). Various animal taxa have a sperm allocation strategy, which is especially well documented in terrestrial insects (e.g. Pitnick 1993, Pitnick \& Markow 1994, Gage \& Barnard 1996, Wedell 1998, Wedell \& Cook
1999, Rondeau \& Sainte-Marie 2001, Pizzari et al. 2003). To maximize their reproductive success, males allocate their sperm reserves depending on various factors. For example, risk of sperm competition (e.g. presence of a rival male) may induce males to increase their sperm number per mating to have a greater fertilization rate (e.g. Gage \& Barnard 1996, Marconato \& Shapiro 1996, Wedell et al. 2002, Pizzari et al. 2003). Males have greater reproductive success by strategically increasing their sperm numbers to females that provide larger fertilization returns (e.g. Gage \& Barnard 1996, Marconato \& Shapiro 1996, Wedell 1998, Wedell \& Cook 1999, Wedell et al. 2002, Pizzari 
et al. 2003). Males also allocate their sperm reserves depending on the probability of how many females will be encountered (e.g. Pitnick 1993, Pitnick \& Markow 1994, Rondeau \& Sainte-Marie 2001, Wedell et al. 2002).

The sperm allocation strategy is sometimes a disadvantage for females due to severe reduction in sperm numbers from males. For example, a femalebiased sex ratio means an increase in future mating opportunities for males, which may cause males to conserve their sperm reserves for future mating opportunities by decreasing the ejaculate size per mating even at the expense of a reduced fertilization rate, that is sperm limitation, because it is less costly to males than depleting their sperm before mating opportunities have ended (Warner et al. 1995). In snow crab Chionoecetes opilio, males prudently allocate their sperm to successive mating by decreasing ejaculate size per mating whem sex ratio (SR) skews toward females (Rondeau \& Sainte-Marie 2001), resulting in sperm limitation in mated females. Theoretical models suggest that the pattern of sperm allocation is more pronounced with increasing variance of female reproductive quality (Galvani \& Johnstone 1998); this pattern also varies with the number of sperm retained by the male at the start of the reproductive season (Galvani \& Johnstone 1998).

In addition, sperm limitation in females may result from a difference in sperm allocation by males of different body sizes. Larger male spiny lobster Panulirus argus adjust the sperm numbers passed to females depending on the body size of females and pass larger ejaculates to larger females. However, smaller males have a limited capacity to increase the ejaculate size, and so larger females that mate with smaller males have smaller clutches (MacDiarmid \& Butler 1999). Therefore, the probability that female fertilization success will be constrained by an insufficient sperm supply may be high in a population in which the SR is skewed toward females or the number of larger males is small.

Fisheries cause changes in population structure. Fisheries in many large decapod crustaceans selectively harvest only large males (e.g. Ennis et al. 1990, Smith \& Jamieson 1991, Abbe \& Stagg 1996, Sato et al. 2005a), which decreases the mean male size and skews the sex ratio toward females in populations (Paul \& Adams 1984, Ennis et al. 1988, Abbe \& Stagg 1996, Sato et al. 2005a). A decrease in male crab density reduces the intensity of male competition for receptive females. Therefore, small mature males may replace fished large males for reproduction (Ennis et al. 1988, 1990, Sainte-Marie 1993). The remaining few larger males and small males mate more often than in non-fished populations (Powell et al. 1974, Ennis et al.
1988, 1990, Sainte-Marie 1993). Thus the probability may increase that females will suffer from sperm limitation due to male sperm allocation. However, compared with terrestrial insects, only a few studies have shown a sperm allocation strategy by marine crustaceans (Jivoff 1997, MacDiarmid \& Butler 1999, Rondeau \& Sainte-Marie 2001). The occurrence of sperm limitation in commercially fished decapod populations have been investigated (e.g. Smith \& Jamieson 1991, Hankin et al. 1997, Paul \& Paul 1997, Kendall et al. 2001, Rondeau \& Sainte-Marie 2001, Sato et al. 2005a), but a comprehensive understanding of the mechanisms that limit sperm passed to females in such fished populations does not exist.

The spiny king crab Paralithodes brevipes inhabits the Sea of Okhotsk off northern Japan and in the Bering Sea (Miyake 1982). It is an important fishery resource off eastern Hokkaido, but catches have declined in recent years. Since 1991, only males larger than $80 \mathrm{~mm}$ carapace width $(\mathrm{CW})$, corresponding to about $69.7 \mathrm{~mm}$ carapace length (CL) from the relationship between CL and CW shown by Mori (1993), have been fished. The fishery for this species starts every year on April 1 at Hamanaka $\left(43^{\circ} 30^{\prime} \mathrm{N}, 145^{\circ} 60^{\prime} \mathrm{E}\right)$ and lasts until July. The male-only fishing decreases the size of males available for mating and skews the SR toward females in the fished population of Hamanaka (Sato et al. 2005a).

Larger males of the spiny king crab have larger sperm reserves and a superior ability to mate with females and to fertilize their clutches successively compared with smaller males (Sato et al. 2005a). In a fished population, the number of sperm retained by males decreases throughout the reproductive season and some males deplete their sperm reserves, so much that they cannot mate, even in the middle of the reproductive season (Sato et al. 2005a). Some mature females are lacking or have only partial clutches, and many females with clutches have a low fertilization rate in fished populations. Temporary shortages of sperm and males for females cause a reduction in the fertilization rate (T. Sato et al. unpubl. data). Thus sperm limitation would exist in the fished populations (Sato et al. 2005a). However, a comprehensive understanding of the mechanisms limiting sperm passed to females in fished spiny king crab populations does not exist. Because the number of mating opportunities for males increases in fished spiny king crab populations, males may allocate their sperm to successive matings by decreasing the ejaculate size at each mating at the expense of a reduced fertilization rate. So far, there is no study examining sperm allocation strategy of the spiny king crab.

The reproductive ecology of this crab has been little studied (Wada et al. 1997, 2000, Sato et al. 2005a,b). 
Our field and laboratory observations have shown that females have one reproductive season from late April to late May per year at Hamanaka and that the receptivity of females is rather synchronous in time. Females molt once in the reproductive season before mating, mate once just after molting (Wada et al. 1997), and usually start to spawn within ca. $1 \mathrm{~h}$ after mating (T. Sato et al. unpubl. data). Females have no spermatheca, so they are highly susceptible to sperm limitation. Females spawn larger numbers of eggs with increasing female body size (Sato \& Abe 1941). Males have a larger amount of sperm with increasing male body size (Sato et al. 2005a). This size-dependent reproduction by each sex may influence the pattern of a sperm allocation strategy by males (Galvani \& Johnstone 1998, Reinhold et al. 2002). To understand the sperm allocation patterns, whether the recovery rate of sperm in vasa deferentia varies with male size should be examined because the recovery rate influences the amount of sperm held by males.

This study examined by 3 laboratory experiments if sperm allocation by males can limit sperm passed to females in fished spiny king crab populations in which large males are selectively fished. We investigated the recovery rate of sperm in vasa deferentia of different male body sizes, the sperm allocation to females of different body sizes by males of different body size, and the sperm allocation strategy at different SR with males of different body sizes.

\section{MATERIALS AND METHODS}

All laboratory experiments were conducted at the Akkeshi Station of the Incorporated Administrative Agency, Fisheries Research Agency, National Center for Stock Enhancement, Hokkaido, Japan, from April to September 2003 and 2004. At this station, many mature spiny king crabs are reared to produce seed crabs for a stock enhancement program. Mature crabs were collected off eastern Hokkaido. Male crabs were collected in early April before the reproductive season in 2003 and 2004. Smaller crabs (<CL $69.7 \mathrm{~mm}$ ) were caught in crab pots at various sites and depths $(<40 \mathrm{~m})$ off the coast of Hamanaka. Larger crabs (>CL $69.7 \mathrm{~mm}$ ) were bought from fishermen who also harvested male crabs off the coast of Hamanaka. The collected males were transported to the Akkeshi Station, and they were sexed by shape of the abdomen. Their CL was measured to the nearest $0.1 \mathrm{~mm}$ with vernier calipers. Only intact individuals with all limbs and nonmolted males in the intermolt stage were used in this study. Crabs were divided into 4 groups based on sex and body size (small male: CL $80-85 \mathrm{~mm}$, large male: CL 100-110 mm, small female: premolt CL $80-85 \mathrm{~mm}$, large female: premolt CL 100-110 mm). Each group was reared in different tanks $\left(8 \mathrm{~m}^{3}\right)$. During the experiments, a light-dark regime matched the local conditions, the water temperature was -0.6 to $4.3^{\circ} \mathrm{C}$, and the water was filtered and aerated. Fresh seawater flowed through all tanks and aquaria, and the crabs were fed shishamo smelt Hypomesus japonicus, shortneck clams Ruditapes philippinarum and sand shrimps Crangon spp.

Expt 1. Relationship between male size and sperm recovery rate. We used 16 small males (CL 80$85 \mathrm{~mm}$ ), 20 large males (CL 100-110 mm) and many nonmolted large females (premolt CL 100-110 mm). Each male was placed in a separate circular aquarium $\left(0.5 \mathrm{~m}^{3}\right)$. We observed large females in an $8 \mathrm{~m}^{3}$ tank every morning. If a female had molted, we transferred it to a circular aquarium that had a male. After the transfer, we checked if the molted female had spawned every morning. After spawning, the spawned female was moved from the circular aquarium and another molted female was transferred to the circular aquarium the next day. If molted females did not spawn within $2 \mathrm{~d}$ after transfer, they were checked for spermatophores attached to their abdomen. Females without spermatophores were transferred to another tank $\left(8 \mathrm{~m}^{3}\right)$ that contained over 30 males to determine if the spawning failure was due to the male or the female. If the female spawned and had a fertilized clutch in the tank with 30 males, we assumed that the male in the circular aquarium was the cause of the spawning failure.

Every male was given access to 1 molted female a day until the male was incapable of inducing a female to spawn within $2 \mathrm{~d}$ after the female molt and transfer. A preliminary examination revealed that all successful matings that induced a female to spawn were within the $2 \mathrm{~d}$. Males that did not induce a female to spawn after more than $2 \mathrm{~d}$ were judged unable to induce the female to spawn; these males were defined as 'depleted males' and were then isolated from other individuals in the separate circular aquarium.

Males store many spermatophores containing many sperm in the vasa deferentia before mating (Sato et al. 2004, 2005a). Only sperm inside the spermatophores in the vasa deferentia is available for mating. To estimate recovery of exhausted sperm, at 0,14 and $28 \mathrm{~d}$ after male depletion, the vasa deferentia were removed and were put into a $50 \mathrm{ml}$ tube filled with $10 \mathrm{ml}$ of $20 \%$ $\mathrm{NaOH}$ solution to extract sperm from the spermatophores (Sato et al. 2004). After $120 \mathrm{~min}$, the tube contents were mixed using a vortex-type mixer. The mixed solution was immediately placed in a Thoma hemacytometer, and the solution was allowed to settle for $3 \mathrm{~min}$. The sperm in $0.1 \mu \mathrm{l}$ of the solution were then counted under an optical microscope at $400 \times$ magnifi- 
cation and medium-high light. The total number of sperm in the vasa deferentia was calculated as: (number of sperm counted/volume of $\mathrm{NaOH}$ counted [i.e. $0.1 \mu \mathrm{l}]) \times$ total volume (i.e. $10 \mathrm{ml}$ ). Four subsamples of $0.1 \mu \mathrm{l}$ were taken, and the sperm were counted in each tube; the average of the 4 counts was used as the number of sperm counted. Simple linear regressions were used to find the relationships between the number of sperm in the vasa deferentia and the number of days after depletion of the males in each male size class. To estimate the recovery rate of exhausted sperm, the vasa deferentia were removed from unmated males (small males, CL 80-85 mm, $\mathrm{n}=11$; large males, CL 100-110 mm, $\mathrm{n}=13$ ) before the reproductive season. We counted the number of sperm in the vasa deferentia retained by the unmated males using the same method as for the above experiment except that a $50 \mathrm{ml}$ tube was filled with $40 \mathrm{ml}$ of $20 \% \mathrm{NaOH}$ solution. The number of sperm retained by unmated males was compared with that of males allowed to recover for $28 \mathrm{~d}$ using the $t$-test for each male size class after logtransformed data sets were tested for homogeneity of variances using the Levene test.

Expt 2. Effects of male and female size on ejaculate size and fertilization rate. To examine the effects of male and female size on the ejaculate size, we used small males (CL 80-85 mm, $\mathrm{n}=18$ ), large males (CL 100-110 mm, $\mathrm{n}=18$ ), non-molting small females (premolt CL 80-85 mm, $\mathrm{n}=16$ ), and non-molting large females (premolt CL 100-110 mm, n = 20). Four groups of male and female pairs were formed: small male and small female, $\mathrm{n}=8$; small male and large female, $\mathrm{n}=$ 10; large male and small female, $\mathrm{n}=8$; large male and large female, $\mathrm{n}=10$.

For each group, one male was placed into a separate circular aquarium $\left(0.5 \mathrm{~m}^{3}\right)$. We observed the tanks containing small or large females every morning to see if they had molted. We transferred a molted female to a circular aquarium to mate with a male, and we observed them until they mated. Because female spiny king crabs have no spermatheca, males attach spermatophores onto the abdomen of females near the gonopores during mating (Sato et al. 2005a). Mated females fertilize their eggs externally within the brood chamber formed by a flap under the body (Sato \& Abe 1941). In this study, the mated female was carefully removed from the water just after mating, and the spermatophores were removed from the fish's abdomen by cutting out parts of the female exoskeleton where the spermatophores were attached. The exoskeleton parts were put into one $15 \mathrm{ml}$ tube filled with $10 \mathrm{ml}$ of $20 \% \mathrm{NaOH}$ solution. The total number of ejaculated sperm was counted and estimated by using the same method as for counting the number of sperm in the vasa deferentia in Expt 1 except for soaking in
$\mathrm{NaOH}$ solution for $60 \mathrm{~min}$ (Sato et al. 2005a). Each male mated only once with a small or large female. The effects of male and female size on the number of ejaculated sperm were analyzed using 2-way ANOVA after log-transformed data sets were tested for homogeneity of variances using the Levene test.

To examine the effects of male and female size on the fertilization rate, we used small males (CL 80$85 \mathrm{~mm}, \mathrm{n}=13$ ), large males (CL 100-110 mm, $\mathrm{n}=12$ ), non-molting small females (premolt CL 80-85 mm, $\mathrm{n}=$ 11), and non-molting large females (premolt CL 100-110 mm, n = 14). Four groups of male and female pairs were formed: small male and small female, $n=6$; small male and large female, $\mathrm{n}=7$; large male and small female, $\mathrm{n}=5$; large male and large female, $\mathrm{n}=7$.

Similar to the experiment on the effect of male and female size on ejaculate size, each male was placed into a separate circular aquarium $\left(0.5 \mathrm{~m}^{3}\right)$ and tanks containing females were observed every morning. If females had molted in the tank, they were transferred individually to a circular aquarium to mate with a male. After the females mated and spawned in the aquarium, they were transported to another tank $\left(2 \mathrm{~m}^{3}\right)$. After about $12 \mathrm{~d}$ postspawning (T. Sato et al. unpubl. data), when spawned and fertilized eggs normally were divided into 32 cells, 150 eggs were randomly collected from 3 parts of the clutch using a pair of tweezers and examined for cell division under a stereomicroscope. We used the percentage of dividing eggs as the fertilization rate of the clutch. Each male mated only once with a small or large female. The effects of male and female size on fertilization rate were analyzed using 2-way ANOVA after logtransformed data sets were tested for homogeneity of variances using the Levene test.

To investigate if small or large females were suitable mates for spiny king crab males to maximize fertilization returns by a finite sperm reserve, we calculated the 'sperm-to-egg ratio', which is the expected number of fertilized eggs for each unit number of sperm passed from male to female. Because all small and large females that mated with large males showed an almost $100 \%$ fertilization rate in the experiment on the effect of male and female size on fertilization rate, we presumed here that all females show a $100 \%$ fertilization rate when they mate with a large male. The sperm-toegg ratio was calculated from (1) ejaculate size from large male to female and (2) expected number of eggs spawned by a mated female calculated from the relationship between the CL of mated females and number of eggs spawned, $\log _{10}$ (number of eggs spawned) = $4.80 \times \log _{10}$ (premolting CL of female) $-4.74, \mathrm{r}^{2}=0.86$, (Sato et al. unpubl. data). In this study, the sperm-toegg ratio indicating the expected number of fertilized eggs for every 10000 sperm passed from a large male 
to a female was calculated as: (expected number of eggs spawned/number of ejaculated sperm) $\times 10000$. The sperm-to-egg ratio was calculated for each pair (large male and small female, $\mathrm{n}=8$; large male and large female, $\mathrm{n}=10$ ). The $t$-test was used to identify significant differences in the sperm-to-egg ratio between different sized females.

Expt 3. Effect of sex ratio on ejaculate size. To examine if ejaculate size varies with male:female SR surrounding males, we used small males (CL $80-85 \mathrm{~mm}$, $\mathrm{n}=19$ ), large males (CL 100-110 mm, $\mathrm{n}=18$ ), and many non-molting large females (premolt CL 100-110 mm). Two groups were formed: small male and large female, $\mathrm{n}=19$; large male and large female, $\mathrm{n}=18$, and we compared the ejaculate size between social circumstances for the different SR (male:female $=1: 1$ or 1:6) of each male size class.

To estimate the ejaculate size for $\mathrm{SR}=1,10$ small and 9 large males were placed in separate circular aquaria $\left(1 \mathrm{~m}^{3}, \mathrm{n}=19\right)$. Similar to the above experiment investigating effect of male and female size on ejaculate size, the tanks containing large females were observed every morning. One molted female in the tank was transported to an aquarium containing a male to mate. After the male and the molted female mated, the ejaculated sperm was collected and estimated. The method of collecting and estimating the number of ejaculated sperm was the same as for counting the number of ejaculated sperm for each male and female size in Expt 2.

To estimate the ejaculate size for $\mathrm{SR}=0.167,10$ small and 9 large males were placed into separate circular aquaria $\left(1 \mathrm{~m}^{3}, \mathrm{n}=19\right)$ at least $2 \mathrm{~d}$ before mating. Five non-molting females were placed in each aquarium containing 1 male about $3 \mathrm{~h}$ before the start of the mating experiment. Most non-molting females were likely to molt soon and be sexually receptive. All males immediately grasped 1 non-molting female, or sometimes more non-molting females simultaneously, which is precopulatory guarding behavior. In the spiny king crab, the SR affects the duration of precopulatory guarding behavior, and the duration was markedly shorter at a female-biased SR (1:5) than at a SR of 1 (Wada et al. 2000), indicating that males can distinguish social circumstances surrounding themselves based on the SR and decide their optimal strategy. Our experiment in this study was done under the same conditions (e.g. SR and aquaria) as the experiments of Wada et al. (2000). At the end of the period to acclimatize for a female-biased sex ratio, 1 molted female in the tank was transported to an aquarium containing a male and 5 non-molting females. After the male and the molted female mated, the ejaculated sperm was collected and ejaculated sperm count estimated depending on male and female sizes in Expt 2.
Each male mated with 1 female per day and with 2 females within $2 \mathrm{~d}$. We compared the number of ejaculated sperm in successive matings between different $\mathrm{SR}$ in each male size class using 2-way repeated measures ANOVA after testing for homogeneity of variances using the Levene test.

\section{RESULTS \\ Expt 1}

After the males were depleted, some sperm remained in the vasa deferentia. The number of sperm in the vasa deferentia of small males and the number of days after males were incapable of mating showed no relationship $(y=0.06 x+10.50$, where $y$ is the number of sperm in vasa deferentia $\left(\times 10^{6}\right)$ and $x$ is the number of days after depletion, $\mathrm{r}^{2}=0.024, \mathrm{n}=16, \mathrm{p}=0.57$ ). The number of sperm in the vasa deferentia differed significantly between unmated males and males allowed $28 \mathrm{~d}$ to recover after depletion $(t$-test, $t=7.78, \mathrm{df}=14$, $p<0.001$, Fig. 1). The number of sperm in the vasa deferentia of the males allowed $28 \mathrm{~d}$ to recover was significantly lower than for unmated males (Fig. 1). Thus, the number of sperm in the vasa deferentia was not even partially recovered even $28 \mathrm{~d}$ postdepletion.

The number of sperm in the vasa deferentia of large males and the number of days after males were incapable of mating had a significant relationship $(y=$ $0.22 x+14.85$, where $y$ is the number of sperm in vasa deferentia $\left(\times 10^{6}\right)$ and $x$ is the number of days after depletion, $r^{2}=0.23, n=20, p=0.031$ ), and the number

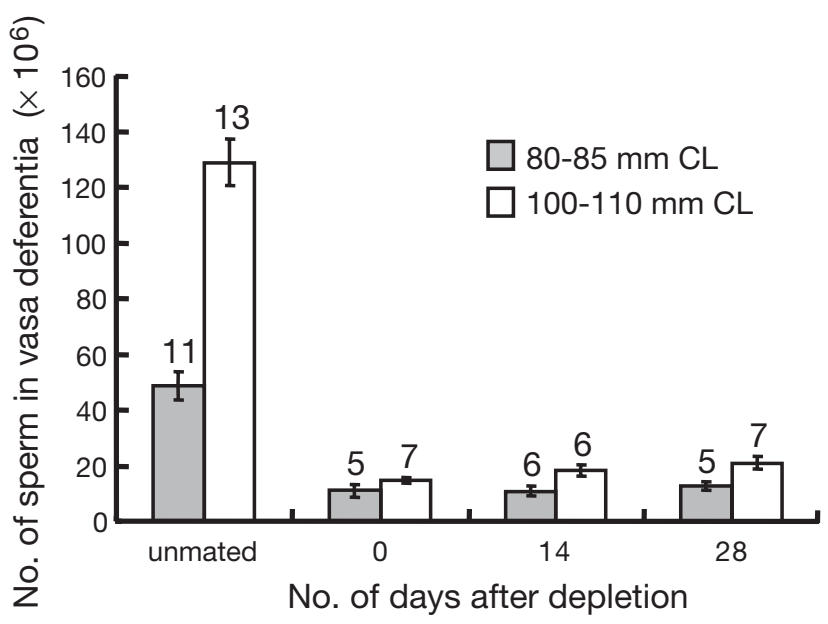

Fig. 1. Paralithodes brevipes. Recovery rate of number of sperm in vasa deferentia and number of sperm in vasa deferentia retained by unmated males by small (CL 80-85 mm) or large (CL 100-110 mm) males. CL: carapace length. Error bars: \pm SE. Numbers above bars: sample size 
of sperm in the vasa deferentia increased with increasing number of days after depletion (Fig. 1). However, the number of sperm in the vasa deferentia of unmated males differed significantly from that of males allowed $28 \mathrm{~d}$ to recover after depletion ( $t$-test, $t=14.39$, df $=18, \mathrm{p}<0.001$ ), and the number of sperm in the vasa deferentia of males allowed $28 \mathrm{~d}$ to recover was significantly lower than for unmated males (Fig. 1). Thus, the number of sperm in the vasa deferentia of large males recovered very little even 28 d post-depletion.

\section{Expt 2}

In all pairs, spermatophores were correctly attached to the female abdomen. 2-way ANOVA showed male and female sizes were significant for the ejaculate size and detected a 2-way interaction between male and female sizes on the ejaculate size (Table 1). In large males, the ejaculate size increased significantly with increasing female size (Fig. 2a), but female size had no effect on the ejaculate size of small males. Thus, the ejaculate size passed to large females by different sized males was significantly different (Fig. 2a). However, despite this, only male size was significant for the fertilization rate (Table 2), male and female sizes showed no interaction for fertilization rate (Fig. 2b), and the fertilization rate of large females mated with small males showed a small difference from that of females mated with large males.

The sperm-to-egg ratio was significantly higher when large males mated with large females than when they mated with small females $(t$-test, $t=-3.53, \mathrm{df}=16$,

Table 1. Paralithodes brevipes. Two-way ANOVA of effects of male and female sizes on number of ejaculated sperm

\begin{tabular}{|lrlrr|}
\hline Source & df & Mean sq. & \multicolumn{1}{c|}{$F$} & \multicolumn{1}{c|}{$\mathrm{p}$} \\
\hline Male size (MS) & 1 & 0.397 & 28.350 & $<0.001$ \\
Female size (FS) & 1 & 0.09113 & 6.513 & 0.016 \\
MS $\times$ FS & 1 & 0.08668 & 6.195 & 0.018 \\
Error & 32 & 0.01399 & & \\
\hline
\end{tabular}

Table 2. Paralithodes brevipes. Two-way ANOVA of effects of male and female sizes on fertilization rate

\begin{tabular}{|lrrcc|}
\hline Source & df & Mean sq. & $F$ & $\mathrm{p}$ \\
\hline Male size (MS) & 1 & 110.912 & 6.854 & 0.016 \\
Female size (FS) & 1 & 21.466 & 1.372 & 0.262 \\
MS $\times$ FS & 1 & 13.065 & 0.807 & 0.397 \\
Error & 21 & 16.182 & & \\
\hline
\end{tabular}

$\mathrm{p}=0.003)$; thus large males had a larger fertilization success for every 10000 sperm passed to females when mated with larger females than when mated with small females (Fig. 3).
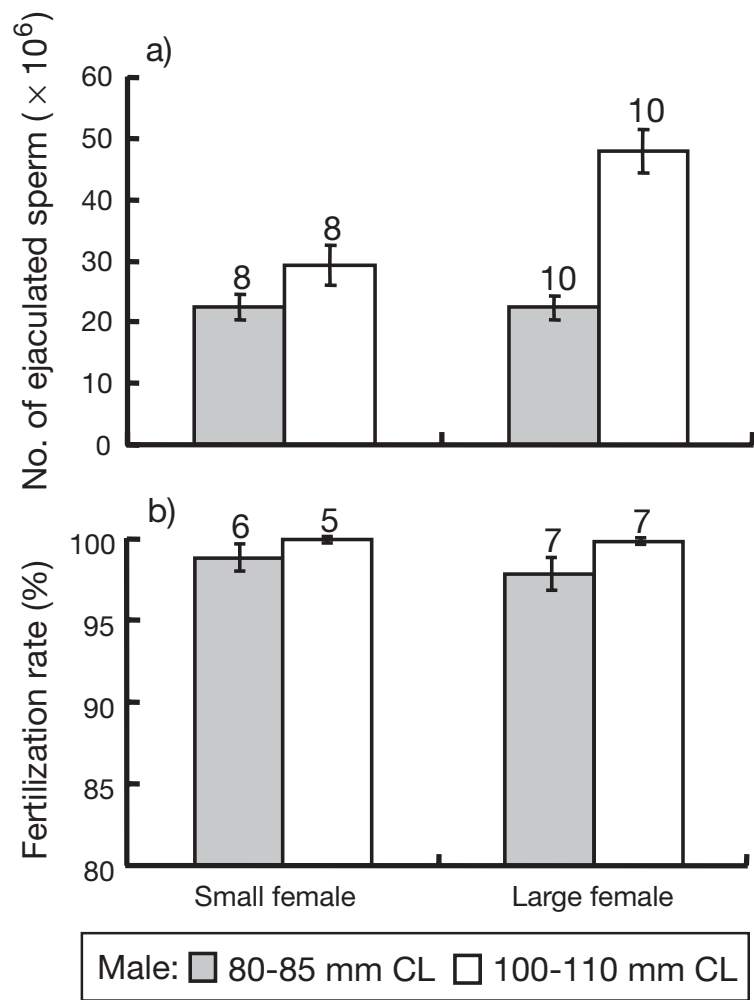

Fig. 2. Paralithodes brevipes. Effect of male and female sizes on (a) number of ejaculated sperm and (b) fertilization rate by small (CL 80-85 $\mathrm{mm}$ ) or large (CL 100-100 mm) males. Small females (premolt CL $80-85 \mathrm{~mm}$ ), large females (premolt CL 100-110 mm). Error bars: \pm SE. Numbers above bars: replicates

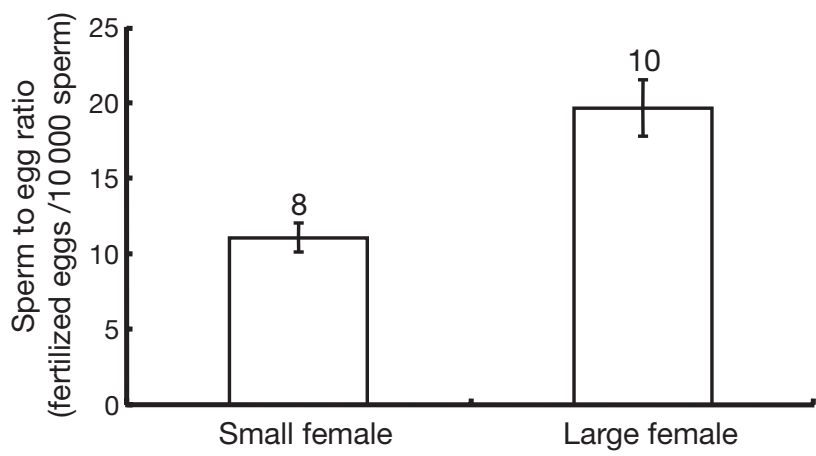

Fig. 3. Paralithodes brevipes. Sperm-to-egg ratio (expected no. of fertilized eggs per 10000 sperm). Small females (premolt CL 80-85 mm), large females (premolt CL 100-110 mm). The sperm-to-egg ratio are for females mated with large males (CL 100-100 mm), assuming 100\% fertilization. Error bars: \pm SE. Numbers above bars: replicates 


\section{Expt 3}

The spermatophores of all pairs were correctly attached to the female abdomen. In both small and large male size classes, 2-way repeated measures ANOVA showed only mating frequency was signifi-

Table 3. Paralithodes brevipes. Two-way repeated measures ANOVA of effects of sex ratio and male mating frequency on number of ejaculated sperm in successive matings by small males (CL 80-85 mm)

\begin{tabular}{|lrrrr|}
\hline Source & df & Mean sq. & \multicolumn{1}{c|}{$F$} & $\mathrm{p}$ \\
\hline Between subjects & & & & \\
Sex ratio (SR) & 1 & 14.671 & 0.464 & 0.505 \\
Error & 17 & 31.618 & & \\
Within subjects & & & & \\
Mating frequency (MF) & 1 & 2780.650 & 117.664 & $<0.001$ \\
SR $\times$ MF & 1 & 0.472 & 0.018 & 0.895 \\
Error & 17 & 23.632 & & \\
\hline
\end{tabular}

Table 4. Paralithodes brevipes. Two-way repeated measures ANOVA of effects of sex ratio and male mating frequency on number of ejaculated sperm in successive matings by large males (CL 100-110 mm)

\begin{tabular}{lrrrr|}
\hline Source & df & Mean sq. & \multicolumn{1}{c}{$F$} & $\mathrm{p}$ \\
\hline Between subjects & & & & \\
Sex ratio (SR) & 1 & 55.254 & 1.304 & 0.270 \\
Error & 16 & 42.387 & & \\
Within subjects & & & & \\
Mating frequency (MF) & 1 & 4268.444 & 96.234 & $<0.001$ \\
SR $\times$ MF & 1 & 6.588 & 0.149 & 0.705 \\
Error & 16 & 44.355 & & \\
\hline
\end{tabular}

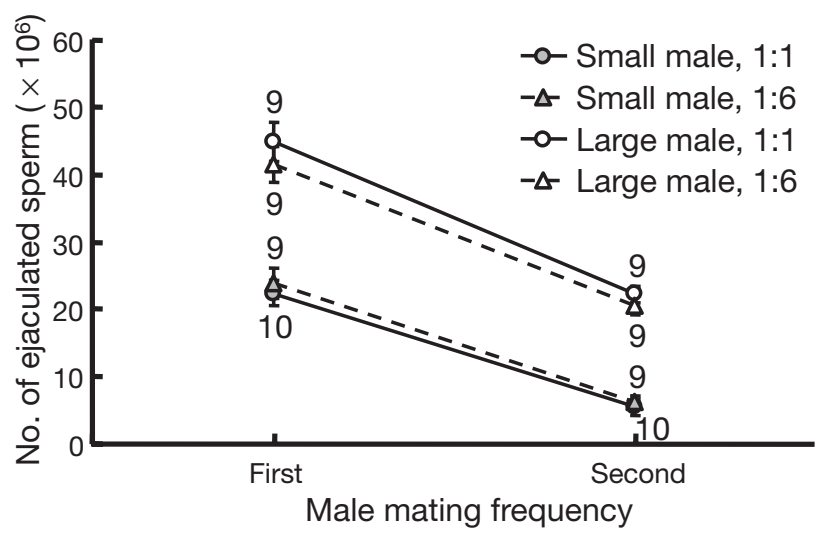

Fig. 4. Paralithodes brevipes. Relationships between male mating frequency and number of ejaculated sperm at different sex ratios (male:female $=1: 1$ or $1: 6$ ) by small (CL $80-85$ $\mathrm{mm})$ vs. large (CL 100-110 mm) males. Error bars: \pm SE. Numbers: replicates cant for ejaculate size and detected no 2-way interaction between SR and mating frequency for ejaculate size (Tables $3 \& 4$ ). Large males always passed larger ejaculates to females than small males regardless of mating frequency, and the ejaculate size decreased with increasing mating frequency (Fig. 4).

\section{DISCUSSION}

Various taxa recover sperm reserves (e.g. Birkhead 1991, Westneat et al. 1998). In large male blue crab Callinectes sapidus, exhausted sperm recovers completely between 9 and 20 d after mating (Kendall et al. 2001). Because large blue crab males typically guard females for 2 to $5 \mathrm{~d}$ before mating (Jivoff 1995), large males that mate may recover some sperm and their seminal fluid by the next mating (Kendall et al. 2001). In this study, large but not small male spiny king crab significantly increased the number of sperm in the vasa defentia with increasing number of days after depletion. However, compared with blue crab, the increase in number of sperm in the vasa defentia of large males was very slight, and it occurred at a slow rate, which suggests that spermatophore production is costly for males. Males are unable to recover most of their sperm reserve before the next mating and would recover their sperm reserve completely by the next reproductive season. This characteristic of the spiny king crab male means males economize on their sperm reserve and allocate their sperm efficiently among successive matings to increase their reproductive success.

In species in which females vary in mate quality, males attain higher reproductive success by allocating larger sperm reserves to females that provide a larger fertilization return (Wedell et al. 2002). Much evidence exists that males provide larger ejaculates to larger females in various species in which female reproductive potential usually depends on body size (e.g. Marconato \& Shapiro 1996, Wedell 1998, MacDiarmid \& Butler 1999, Wedell \& Cook 1999). Large spiny king crab males also adjust the ejaculate size depending on female size and pass larger ejaculates to larger females, which are more fecund than small females (Sato \& Abe 1941). Large sperm numbers passed to large females result from the fact that the sperm efficiency is significantly higher when males mate with large females than when males mate with small females, that is, larger females provide larger fertilization returns.

The ejaculate size of small males did not vary with female size, indicating small males cannot increase the ejaculate size more than a certain number (ca. $22.5 \times$ $10^{6}$ sperm, Fig. 2a). Small spiny lobster males have a limited capacity to increase the ejaculate size with 
increasing female size, and clutches of large females that mate with a smaller male are significantly smaller than clutches fertilized by a larger male because sperm supplies from the smaller males are insufficient for complete fertilization (MacDiarmid \& Butler 1999). This female struggle with insufficient sperm supply by small males is likely in spiny king crab. However, in this study, the fertilization rate of large females mated with small males showed only a small difference from that of large females mated with large males, even though the small spiny king crab males also passed significantly smaller ejaculates to large females than did larger males.

This discrepancy may result from artificial environments in the experimental aquaria in which the females spawned and fertilized their clutches: the aquaria had little water current even though aerated seawater flowed through all aquaria. In free-spawning species, the fertilization rate decreases as the velocity of water current increases around spawning females at spawning (Pennington 1985, Denny \& Shibata 1989), mainly due to dilution of the sperm in the water. Spiny king crab females spawn and fertilize their eggs externally within the brood chamber formed by a flap under the body. This process of fertilizing eggs increases the chance of sperm loss and decreases the fertilization rate (Subramoniam 1993), and the amount of loss and decrease is influenced by the velocity of the water current around spawning females at fertilization.

Smaller male stone crab, Hapalogaster dentata, in which the process of fertilizing eggs is the same as in the spiny king crab, pass much smaller ejaculates to larger females than do larger males (T. Sato et al. unpubl. data). However, when larger females mate with smaller or larger males in an aquarium without a water current, the fertilization rate of the females mated with smaller males does not differ from females mated with larger males, and it is high. However, when larger females mate with smaller or larger males in a natural habitat with a water current (velocity of water current: mean $\pm \mathrm{SE}, 4.04 \pm 0.14 \mathrm{~cm} \mathrm{~s}^{-1}$ ), the fertilization rate of females mated with smaller males is markedly lower than for females mated with larger males (small male $\times$ large female: $83.8 \%$, large male $\times$ large female: $99.9 \%$, T. Sato et al. unpubl. data). Thus, fertilization rate is influenced by the water current around spawning females.

In this study, the result that small males had disproportionate high fertilization rates by passing marked smaller ejaculates than did large males may have been caused by the artificial environment without a water current in the experimental aquarium. Judging from the difference in ejaculate size passed to large females by different sized males, the sperm supply from small males would be insufficient to fertilize a whole clutch spawned by large females in the field. The reproductive success of such larger females may be limited by sperm limitation in fished populations with few males larger than females. In the future, we should examine the relationship between fertilization rate and the velocity of water current around a female.

The reproductive success of females may be limited by female mate choice, which is seen in various animals, including crustacean species (Snedden 1990, Jormalainen et al. 2000, Díaz \& Thiel 2003). Female mate choice should evolve whenever males differ in ability to fertilize eggs (Trivers 1972). Spiny king crab females should avoid mating with small males that pass an insufficient sperm supply, and especially larger females that spawn many eggs should be more selective in choosing mates compared with smaller females. However, larger females have difficulty in finding males larger than themselves in fished spiny king crab populations because of the size-selective fishery (Sato et al. 2005a). If females have such a choice criterion, females may delay mating due to a decrease in availability of suitable mates and may fail to mate within the optimal period after molting (Sato et al. 2005b), resulting in a decrease in reproductive success of females. Because larger females spawn many eggs (Sato \& Abe 1941), larger females have a great impact on the reproductive rate of populations. Studies to determine if large females successfully mate with males and spawn in the fished populations would be of great importance.

In most animals, mate choice is usually made by females because the reproductive investment of females is thought to be larger than for males (Trivers 1972). However, males also choose mates in reproductive systems with relatively higher male reproductive investment or in cases in which the number of male matings is limited (Wiernasz 1995). Crustacean species also have male mate choice (Shuster 1981, Wen 1993, Goshima et al. 1996). The sperm recovery rate of the spiny king crab is very slow, and the number of matings by males is few due to limited sperm reserves (Sato et al. 2005a). Therefore, males must maximize reproductive success by efficiently allocating their limited sperm reserves to females that provide larger fertilization returns. Males should be selective in choosing mates. In this study, the sperm-to-egg ratio was significantly higher for males mating with large females than for males mating with small females, indicating that large females have a high quality as mates and therefore males with limited sperm reserves can maximize their reproductive success by mating with large females. Spiny king crab males may prefer large females as mates. Little is known of the relationship between the sperm-to-egg ratio varying with female size and male mate choice. 
In this study, the pattern of sperm allocation of spiny king crab males showed no difference between the different SR in both male size classes. However, snow crab males allocate their sperm among successive matings by decreasing the ejaculate size at each mating and pass insufficient sperm for successful fertilization when the SR becomes heavily skewed toward females (Rondeau \& Sainte-Marie 2001), resulting in sperm limitation in the mated female. Snow crab males usually risk sperm competition whenever males mate with a female because females can be polyandrous (SainteMarie et al. 1997, 1999). Snow crab males cannot predict when they can mate with females with low risk of sperm competition. In addition, the last male that inseminates a female just before spawning usually has paternity through sperm stratification in the spermatheca of snow crab (Urbani et al. 1998, Sainte-Marie et al. 2000). An optimal sperm allocation strategy to maximize male reproductive success is to mate with as many females as possible by decreasing the ejaculate size at each mating. Snow crab behaviour can be explained by sperm competition theory (Pitnick \& Markow 1994, Parker et al. 1997). Therefore, snow crab males decrease their ejaculate size in response to increased female availability to maximize their number of mates (Rondeau \& Sainte-Marie 2001).

Spiny king crab females would be monandrous because they have no spermatheca and the period between mating and spawning is very short (ca. $1 \mathrm{~h}$ ) (T. Sato et al. unpubl. data), indicating that males may have less risk of sperm competition and that 1 male fertilizes the whole clutch of a female. In addition, large spiny king crab females with the lower sperm-to-egg ratio molt and mate earlier in the reproductive season compared with small females with low sperm efficiency (T. Sato et al. unpubl. data), indicating that more beneficial mating opportunities for males occur early in the reproductive season. Males should attempt to mate early in the reproductive season with large females to invest efficiently their limited sperm reserve. Even if many future mating opportunities exist in a reproductive season, it is not adaptive for males to conserve their sperm reserve for future mating opportunities and allocate equally among successive matings because mating with smaller females means a higher sperm-to-egg ratio than mating with larger females. Males should exhaust their sperm reserve as early as possible in the reproductive season to mate with larger females and to avoid mating with smaller females. Therefore, in this study, spiny king crab males did not change the ejaculate size in response to an increase in number of females when the SR skewed toward females. In order to maximize make reproductive success, it is important to allocate an optimal sperm number to females depending on female size, and to mate with larger females with a lower sperm-toegg ratio, i.e., to finish their sperm reserve as early as possible in the reproductive season.

Our study suggests that spiny king crab males have no sperm allocation strategy in response to a change in $\mathrm{SR}$, indicating that a SR skewed toward females due to male-only fishing have no effect on the sperm allocation strategy and does not limit sperm passed to females in fished populations. However, spiny king crab males showed a size-dependent ability to increase the ejaculate size at each mating with increasing female size. A decrease in mean male size due to the male-only fishing would increase the number of females mated with small males without a capacity to increase the ejaculate size more than a certain number, which results in females receiving an insufficient sperm supply and showing a low fertilization rate due to sperm limitation. The present fishery regulations for the spiny king crab may be based on an oversimplified concept of the reproductive system of this species. To maintain the resource of the spiny king crab, these regulations, particularly the minimum legal size, based on the reproductive potential of male size, should be reconsidered. Also, for other large crustacean species that have similar male-only fishing regulations (e.g. MacDiarmid \& Butler 1999, Rondeau \& Sainte-Marie 2001), we should investigate the details of the reproductive ecology of each species to maintain resources.

Acknowledgements. We thank A. Nishiki for providing us with samples, facilities and valuable advice, and other members of the IAA, FRA, National Center for Stock Enhancement, Akkeshi Station, who kindly helped us with the experiments. We also thank all members of the Laboratory of Marine Biodiversity, Graduate School of Fisheries Sciences, Hokkaido University, for their discussions. This work was made possible by the generous hospitality and cooperation of the fishermen and staff of Hamanaka Fishermen's Cooperative Association.

\section{LITERATURE CITED}

Abbe GR, Stagg C (1996) Trends in blue crab (Callinectes sapidus Rathbun) catches near Calvert Cliffs, Maryland, from 1968 to 1995 and their relationship to the Maryland commercial fishery. J Shellfish Res 15:751-758

Birkhead TR (1991) Sperm depletion in the Bengalese finch, Lonchura atriata. Behav Ecol 2:267-275

Denny MW, Shibata MF (1989) Consequence of surfzone turbulence for settlement and external fertilization rate. Am Nat 134:859-889

Dewsbury DA (1982) Ejaculate cost and male choice. Am Nat 119:601-610

Díaz ER, Thiel M (2003) Female rock shrimp prefer dominant males. J Mar Biol Assoc UK 83:941-942

Ennis GP, Hooper RG, Taylor DM (1988) Functional maturity in small male snow crabs (Chionoecetes opilio). Can J Fish Aquat Sci 45:2106-2109

Ennis GP, Hooper RG, Taylor DM (1990) Changes in the composition of snow crab (Chionoecetes opilio) participating in 
the annual breeding migration in Bonne Bay, Newfoundland. Can J Fish Aquat Sci 47:2242-2249

Gage AR, Barnard CJ (1996) Male crickets increase sperm number in relation to competition and female size. Behav Ecol Sociobiol 38:227-237

Galvani A, Johnstone R (1998) Sperm allocation in an uncertain world. Behav Ecol Sociobiol 44:161-168

Goshima S, Koga T, Murai M (1996) Mate acceptance and guarding by male fiddler crabs Uca tetragonon (Herbst). J Exp Mar Biol Ecol 196:131-143

Hankin DG, Butler TH, Wild PW, Xue QL (1997) Does intense fishing on males impair mating success of female Dungeness crab? Can J Fish Aquat Sci 54:655-669

Jivoff PR (1995) The role of mate guarding, male size, and male investment on individual reproductive success on the blue crab, Callinectes sapidus. PhD dissertation, University of Maryland, College Park, MD

Jivoff PR (1997) The relative roles of predation and sperm competition on the duration of the post-copulatory association between the sexes in the blue crab, Callinectes sapidus. Behav Ecol Sociobiol 40:175-185

Jormalainen V, Merilaita S, Härdling R (2000) Dynamics of intersexual conflict over precopulatory mate guarding in 2 populations of the isopod Idotea baltica. Anim Behav 60: 85-93

Kendall MS, Wolcott DL, Wolcott TG, Hines AH (2001) Reproductive potential of individual male blue crabs, Callinecetes sapidus, in a fished population: depletion and recovery of sperm number and seminal fluid. Can J Fish Aquat Sci 58:1168-1177

MacDiarmid AB, Butler MJ (1999) Sperm economy and limitation in spiny lobsters. Behav Ecol Sociobiol 46:14-24

Marconato A, Shapiro DY (1996) Sperm allocation, sperm production and fertilization rates in the bucktooth parrotfish. Anim Behav 52:971-980

Miyake S (1982) Japanese crustacean decapods and stomatopods in color. Vol I. Macrura, Anomura, and Stomatopoda. Hoikusya, Osaka (in Japanese)

Mori Y (1993) Investigation of spiny king crab Paralithodes brevipes resource. Sci Rep Hokkaido Kushiro Fish Exp Stn, p 199-203 (in Japanese)

Parker GA, Ball MA, Stockley P, Gage MJG (1997) Sperm competition games: a prospective analysis of risk assessment. Proc R Soc Lond Ser B 264:1793-1802

Paul AJ, Adams AE (1984) Breeding and fertile period for female Chionoecetes bairdi (Decapoda, Majidae). J Crustac Biol 4:589-594

Paul AJ, Paul JM (1997) Breeding success of large male red king crab Paralithodes camtschaticus with multiparous mates. J Shellfish Res 16:379-381

Pennington JT (1985) The ecology of fertilization of echinoid eggs: the consequence of sperm dilution, adult aggregation, and synchronous spawning. Biol Bull 169: $417-430$

Pitnick S (1993) Operational sex ratio and sperm limitation in populations of Drosophila pachea. Behav Ecol Sociobiol 33:383-391

Pitnick S, Markow TA (1994) Male gametic strategies: sperm size, testes size, and the allocation of ejaculate among successive mates by sperm-limited fly Drosophila pachea and its relatives. Am Nat 143:785-819

Pizzari T, Cornwallis CK, Løvlie H, Jakobsson S, Birkhead TR (2003) Sophisticated sperm allocation in male fowl. Nature 426:70-74

Powell GC, James KE, Hurd CL (1974) Ability of male king crab, Paralithodes camtschatica, to mate repeatedly, Kodiak, Alaska, 1973. Fish Bull US 72:171-179
Reinhold K, Kurtz L, Engqvist L (2002) Cryptic male choice: sperm allocation strategies when female quality varies. J Evol Biol 15:201-209

Rondeau A, Sainte-Marie B (2001) Variable mate-guarding time and sperm allocation by male snow crab (Chionoecetes opilio) in response to sexual competition, and their impact on the mating success of females. Biol Bull 201: 204-217

Sainte-Marie B (1993) Reproductive cycle and fecundity of primiparous and multiparous female snow crab, Chionoecetes opilio, in the northwest Gulf of Saint Lawrence. Can J Fish Aquat Sci 50:2147-2156

Sainte-Marie B, Sévigny JM, Gauthier Y (1997) Laboratory behavior of adolescent and adult males of the snow crab (Chionoecetes opilio) (Brachyura: Majidae) mated noncompetitively and competitively with primiparous females. Can J Fish Aquat Sci 54:239-248

Sainte-Marie B, Urbani JM, Sévigny JM, Hazel F, Kuhnlein U (1999) Multiple choice criteria and the dynamics of assortative mating during the first breeding season of female snow crab Chionoecetes opilio (Brachyura, Majidae). Mar Ecol Prog Ser 181:141-153

Sainte-Marie G, Sainte-Marie B, Sévigny JM (2000) Ejaculate-storage patterns and the site of fertilization in female snow crabs (Chionoecetes opilio: Brachyura, Majidae). Can J Zool 78:1902-1917

Sato S, Abe Y (1941) Fecundity of the king crab, Paralithodes brevipes. Sci Rep Hokkaido Fish Exp Stn 481:244-246 (in Japanese)

Sato T, Ashidate M, Goshima S (2004) A new method to extract sperm from spermatophores of the male spiny king crab Paralithodes brevipes (Anomura: Lithodidae). Crustac Res 33:10-14

Sato T, Ashidate M, Wada S, Goshima S (2005a) Effects of male mating frequency and male size on ejaculate size and reproductive success of female spiny king crab, Paralithodes brevipes. Mar Ecol Prog Ser 296:251-262

Sato T, Ashidate M, Goshima S (2005b) Negative effects of delayed mating on the reproductive success of female spiny king crab, Paralithodes brevipes. J Crustac Biol 25: 105-109

Shuster SM (1981) Sexual selection in the Socorro isopod, Thermosphaeroma thermophilium (cole) (Crustacea: Peracardida). Anim Behav 29:698-707

Smith BD, Jamieson GL (1991) Possible consequences of intensive fishing for males on the mating opportunities of Dungeness crabs. Trans Am Fish Soc 120:650-653

Snedden WA (1990) Determinants of male mating success in the temperate crayfish Orconectes rusticus: chela size and sperm competition. Behaviour 115:100-113

Subramoniam T (1993) Spermatophores and sperm transfer in marine crustaceans. Adv Mar Biol 29:129-214

Trivers RL (1972) Parental investment and sexual selection. In: Campbell B (ed) Sexual selection and the descent of man. Aldine, Chicago, IL, p 136-179

Urbani N, Sainte-Marie B, Sévigny JM, Zadworny D, Kuhnlein U (1998) Sperm competition and paternity assurance during the first breeding period of female snow crab Chionoecetes opilio (Brachyura: Majidae). Can J Fish Aquat Sci 55:1104-1113

Wada S, Ashidate M, Goshima S (1997) Observations on the reproductive behavior of the spiny king crab Paralithodes brevipes (Anomura: Lithodidae). Crustac Res 26:56-61

Wada S, Ashidate M, Yoshino K, Sato T, Goshima S (2000) Effects of sex ratio on egg extrusion frequency and mating behavior of the spiny king crab Paralithodes brebipes (Decapoda: Lithodidae). J Crustac Biol 20:479-482 
Warner RR, Shapiro DY, Marconato A, Petersen CW (1995) Sexual conflict-males with the highest mating success convey the lowest fertilization benefits to females. Proc R Soc Lond Ser B 262:135-139

Wedell N (1998) Sperm protection and mate assessment in the bushcricket Coptaspis sp. 2 (Orthoptera: Tettigoniidae). Anim Behav 56:357-363

Wedell N, Cook PA (1999) Butterflies tailor their ejaculate in response to sperm competition risk and intensity. Proc $\mathrm{R}$ Soc Lond Ser B 266:1033-1039

Wedell N, Gage MJG, Parker GA (2002) Sperm competition,

Editorial responsibility: Otto Kinne (Editor-in-Chief), Oldendorf/Luhe, Germany male prudence and sperm limited females. Trends Ecol Evol 17:313-320

Wen YH (1993) Sexual dimorphism and mate choice in Hyalella azteca (Amphipoda). Am Midl Nat 129:153-160

Westneat DF, McGraw LA, Fraterrigo JM, Birkhead TR, Fletcher F (1998) Patterns of courtship behaviour and ejaculate characteristics in male red-winged blackbirds. Behav Ecol Sociobiol 43:161-171

Wiernasz DC (1995) Male choice on the basis of female melanin pattern in Pieris butterflies. Anim Behav 49: $45-51$

Submitted: January 31, 2005; Accepted: October 15, 2005 Proofs received from author(s): March 23, 2006 